\title{
A LUZ COMUM DO UNIVERSO: tipografia, publicidade e opinião no Portugal moderno. O caso da aclamação de D. João IV em Barcelos (1640-1642)
}

Daniel Saraiva*

RESUMO: Este artigo analisa a relação entre publicidade, política e opinião comum no Portugal do século XVII. O caso da aclamação de D. João IV em Barcelos serve para ilustrar as implicações políticas do que chamamos de "desmaterialização" do público durante a Era Moderna.

PALAVRAS-CHAVE: Publicidade; Opinião pública; Política popular; Restauração de Portugal.

The common light of the universe: typography, publicity and opinion in Early Modern Portugal. The case of the acclamation of John IV in Barcelos (1640-1642)

ABSTRACT: This article analyses the relationship between publicity, politics and common opinion in seventeenth-century Portugal. The case of the acclamation of John IV in Barcelos serves to illustrate the political implications of what we call the "dematerialization" of the public during the Early Modern Period.

KEYWORDS: Publicity; Public opinion; Popular politics; Portuguese restoration.

\section{La luz común del universo: tipografía, publicidad y opinión en el Portugal Moderno. El caso de la aclamación de D. Juan IV en Barcelos (1640-1642)}

RESUMEN: Este artículo examina la relación entre publicidad, política y opinión común en el Portugal del siglo XVII. El caso de la aclamación de D. Juan IV en Barcelos sirve para ilustrar las implicaciones políticas de lo que llamamos la "desmaterialización" del público en la Edad Moderna.

PALABRAS CLAVE: Publicidad; Opinión común; Política popular; Restauración de Portugal.

\footnotetext{
*Doutor em História pela Université Paris IV (Sorbonne). Atualmente é pós-doutorando em História pela Universidade Federal do Rio de Janeiro (UFRJ). Mestre e bacharel em História pela UFRJ. Contato: Instituto de História, Largo de São Francisco de Paula, no 1, CEP:20051-070, Rio de Janeiro, Brasil. E-mail: danielmpsaraiva@gmail.com. ORCID: http://orcid.org/0000-0003-0107-7985.
} 
O lux immensi publica mundi (“Ó, luz comum do imenso universo"): eis como, nas Metamorfoses de Ovídio (2, 35), Phaethon se dirige a seu pai Phebus, o sol, a fim de confirmar se sua mãe Clymene lhe havia dito a verdade sobre sua origem. No belo verso do poeta romano, que se tornaria um topos da literatura moderna ${ }^{1}$, o termo "público", em sua forma adjetiva, aparece como sinônimo de "comum". De fato, na língua latina, a idéia de "público", nas suas diferentes ocorrências e variações, designa de ordinário aquilo que é ou se torna comum e, por conseguinte, aquilo que concerne ou pertence ao povo, seja este entendido no sentido de comunidade política (respublica) ou de multidão - o “comum dos homens" (vulgo). Fala-se, então, em publica commoda (as vantagens de que gozam todos os cidadãos), verba publica (as palavras empregadas por toda a gente), publica (a prostituta, a mulher de todos), lux publica mundi (o sol, a luz de todos). O substantivo publicum, por sua vez, indica o domínio público, o tesouro público, os arquivos públicos, a coisa pública, o interesse público, a multidão, o conjunto de espectadores de um feito realizado em público. Do mesmo modo, o verbo publicare remete a ações diversas, como incorporar um bem à república (confiscar em proveito do Estado), inscrever em registro público um ato privado para conferir-lhe autenticidade e publicidade oficiais (testamentum publicare, apud magistratus donationes publicare) ou destinar algo ao proveito comum, quer se trate de terras públicas (publicare Aventinum) ${ }^{2}$, de bibliotecas públicas (publicare bibliothecas) ou, por extensão, do corpo das mulheres públicas (publicare pudicitiam) ${ }^{3}$.

Ao sentido de partilhar, de tornar comum (communicare), soma-se ainda o de levar ao conhecimento de todos. Note-se, a propósito, que, quando se trata da difusão de uma mensagem, um rumor ou um livro, encontramos ao lado do verbo publicare outros como vulgare, divulgare ou pervulgare, cujo radical explicita de forma ainda mais evidente a íntima relação que se podia estabelecer entre a publicação e os homens comuns ${ }^{4}$. Não é por acaso, afinal, que a bíblia de São Jerônimo se intitula Vulgata. Tampouco é fortuito que esse tenha sido o primeiro livro impresso por Gutenberg ${ }^{5}$, cuja invenção contribuiu de modo decisivo para que "publicar" viesse a tornar-se, mais do que nunca, sinônimo de "vulgarizar".

Com efeito, após o advento da ars artificialiter scribendi, as ambigüidades de que as referidas palavras se faziam portadoras ganharam um novo significado. A tensão entre 
“comunidade política" e "multidão", que na Roma clássica encarnara os conflitos de uma república cuja natureza aristocrática se via amiúde ameaçada pelas reivindicações das camadas plebéias ávidas por participar do exercício do poder ${ }^{6}$, atualiza-se na Era Moderna à medida que o uso do impresso como instrumento de intervenção se generaliza $^{7}$ e as monarquias européias se vêem sacudidas por agitações populares de grandes proporções ${ }^{8}$.

O dilema pode ser formulado da seguinte maneira: o movimento de expansão e mutação das formas de comunicação política tende a confundir-se com um movimento de vulgarização da própria política ou, para dizê-lo de outro modo, de conversão da coisa pública em coisa da plebe. Ao alargar até o "comum dos homens" o público dos debates políticos, a tipografia contribuiu para fragilizar a distinção tradicional entre "república" e "multidão". Como postula Frédéric Barbier, a imprensa favorecia a polêmica na medida em que fixava publicamente as opiniões e, retirando a discussão "dos micro-meios bem isolados", constituía "um movimento geral" de proporções e implicações tão imprevisíveis como incontroláveis. Ao grafar na página inalterável do papel impresso as idéias e posições dos autores, a "rigidez tipográfica" não apenas facilitava a formação de grupos de opinião, mas potencializava os dissensos. O caso paradigmático, sem dúvida, é o das reformas religiosas, cuja repercussão não pode ser pensada independentemente das controvérsias impressas que geraram. Não por acaso os adversários das igrejas reformadas acusaram seus líderes de popularizarem (leia-se "vulgarizarem", no sentido pejorativo do termo) a reflexão sobre os textos sagrados: "o Novo Testamento de Lutero foi de tal maneira multiplicado e difundido pelos editores" - lamenta o católico Cochlæus, o qual desafiara Lutero para um duelo teológico - "que até mesmo os alfaiates e os sapateiros (...), as mulheres, os ignorantes que aceitaram esse novo Evangelho luterano e que sabem ler um pouco de alemão, estudaram-no avidamente como a fonte de toda a verdade" 9 . De fato, em tempos em que a guerra religiosa e civil, o regicídio e a sublevação popular (de que a figura de Masaniello seria um dos maiores ícones ${ }^{10}$ ) pairavam como um espectro sobre a Europa, o potencial desestabilizador e subversivo dos confrontos de opinião adquire uma concretude dramática. Não causa espanto, portanto, que a reflexão sobre a erosão da ordem estabelecida e a reversão das hierarquias 
do mundo ${ }^{11}$ tenha assumido, não raro, a forma de uma crítica dos efeitos perversos da arte tipográfica ${ }^{12}$.

Em que pese o impacto da publicação impressa sobre a dinâmica política européia, os movimentos de opinião não foram, contudo, apanágio da Era Moderna e muito menos do período liberal, ainda que a pseudo-sacralidade que a noção de "opinião pública" alcançou na linguagem contemporânea torne inconcebível, para muitos de seus herdeiros intelectuais, que antes da consagração dessa prosopopéia iluminista na cultura ocidental houvesse outros modos de representar o juízo das populações, sobretudo no que concerne aos assuntos da vida comum ${ }^{13}$. Entre eles, destaca-se a idéia de "Fama", que durante séculos caracterizou a maneira pela qual os povos europeus perceberam os processos de formulação, comunicação e interação das opiniões coletivas. Com efeito, a imagem da deusa romana, filha da Terra e irmã do Caos - imortalizada por Virgílio na figura de um monstro alado que, com sua miríade de bocas, línguas e orelhas, passava as noites a voar sem descanso, ouvindo tudo o que era dito e levando a todos mentiras misturadas com verdades -, impôs-se durante a Idade Média como a alegoria por excelência da "voz pública" (publica vox et fama), indício claro da viva consciência que então se tinha do peso social do juízo comunitário ${ }^{14}$.

A adjetivação que empregamos não é, bem entendido, casual: o assim chamado “Antigo Regime" 15 desconheceu a noção de "indivíduo". Os homens daquele tempo não se entendiam como átomos dispersos na paisagem fragmentada de uma sociedade artificial, fruto de um contrato voluntarista, mas como membros de comunidades (a família, a paróquia, a aldeia, a confraria, a guilda, a comuna, a pátria, etc.) às quais se atribuía muitas vezes um caráter natural ${ }^{16}$. Tratava-se, em verdade, de grupos humanos fundados em relações de convívio e interdependência de que dificilmente se podia escapar e que produziam efeitos imperiosos sobre as trajetórias pessoais. Daí que, do mais ínfimo dos camponeses ao mais poderoso dos príncipes, todos cultivassem à época uma verdadeira obsessão pela fama, a reputação, o renome, concebidos como espelhos vivos da opinião da comunidade. Compreende-se, destarte, por que, ao contrário da “opinião pública” das Luzes, o juízo comunitário plasmado na idéia de Fama possuía uma espécie de vocação "inquisitorial"17, traduzida pela nítida percepção, manifesta inequivocamente pelos contemporâneos, que seu comportamento era constantemente 
avaliado pelo olhar onipresente e severo da voz pública, de cuja aprovação dependia a integridade de sua vida social, tão imprescindível à sua existência como o bom funcionamento de seus órgãos vitais. Afinal, se era possível, como se acreditava, superar a morte perpetuando-se na memória da coletividade, podia-se "reputar por já morto" para retomar os termos de um panfleto anônimo sobre a tentativa frustrada de assassinar D. João IV em 1647 - quem tivesse "decaído da vida da fama”, pois aquele que a perde "é mais que morto"

Assemelhando-se a uma versão mundana da queda adâmica, a infâmia equivale, por conseguinte, a uma morte social, implicando a perda, relativa ou total, provisória ou definitiva, dos bens que a vida comunitária oferece. Toda injúria deve, desse modo, ser lavada, mesmo que seja com sangue. Caso contrário, ela se torna, para todos os efeitos, real. E não se lava uma injúria longe dos olhos do público ${ }^{19}$. Impõe-se, assim, uma lógica de produção de publicidade caracterizada a um só tempo por um forte componente cênico e uma rígida inscrição espacial: em geral, é realizando gestos simbólicos em espaços que permitem a aglomeração da gente (praças, igrejas, tavernas, mercados, tendas, barbearias, farmácias) que um ato deixa o domínio privado - que, neste caso, é o domínio da inexistência (ou da existência insignificante) - e adentra o domínio do público, passando a existir para os outros. Ainda que a fama "corra" na forma de rumor ${ }^{20}$ - como a "opinião" do Cristo a espalhar-se pela Síria ("Et abiit opinio eius in totam Syriam", Mateus, 4, 24) - ou por força do texto manuscrito ${ }^{21}$, sua origem e seu caráter público remontam em geral a um lugar onde algo foi feito diante de um conjunto de espectadores.

Tal relação está claramente configurada, por exemplo, na primeira das definições que propõe Bluteau do termo "publicação". Segundo o erudito, tal palavra designa a "acção de manifestar autenticamente algũa cousa por ordem do Magistrado nos lugares publicos da Cidade, para que fique notoria a todos". E complementa, mais à frente: "tambem se diz de outras cousas, que se manifestão a varias pessoas juntas no mesmo lugar". Em ambos os casos, a publicidade aparece como uma propriedade do espaço que se comunica aos ditos e feitos nele realizados, pois é lá que se reúnem as pequenas ou grandes multidões que, encarnando o olhar da comunidade, darão vida à fama dos acontecimentos. Eis por que, nesse período, a publicação está geralmente associada ao som. "Publicar", diz Bluteau, é "Fazer alguma cousa publica com prégação, ou 
trombeta" ${ }^{, 2}$. Trata-se, bem entendido, dos códigos sonoros da vida comunal, empregados para conclamar a coletividade a testemunhar ou realizar os atos que dizem respeito a todos. É a trombeta que convoca os súditos a tomar ciência da promulgação de novas leis, o clarim que anuncia aos soldados a chegada do inimigo, o sino que chama os fiéis à igreja e os cidadãos ao senado da câmara. Mas se os usos codificados do som servem a conclamar a comunidade, erigindo assim o teatro da publicidade, o clamor comum constitui - como sublinham Didier Lett e Nicolas Offenstadt - a modalidade por excelência de publicação ritual da opinião coletiva, seja para aclamar os príncipes, lançar a revolta, fazer e desfazer as reputações ou manifestar as emoções e exigências gerais ${ }^{23}$.

A inscrição espacial própria da fama medieval se altera, todavia, com o advento da tipografia. As novas possibilidades técnicas trazidas pela revolução de Gutenberg liberam progressivamente os discursos políticos de sua dependência geográfica. A partir de então, a esfera dos debates começa, por assim dizer, a "desmaterializar-se". A produção da publicidade vai perdendo as raízes que a prendiam aos espaços públicos, ainda que estes continuem a funcionar como caixas de ressonância dos rumores, das notícias, das conversas e das opiniões. Inicia-se, em verdade, o lento processo de substituição do público medieval, concebido antes de tudo como um público de testemunhas, pelo público moderno, formado pelos que lêem ou ouvem ler - o mesmo a que se referiu Kant quando concebeu o que chamou de "uso público da razão",24.

Tal fenômeno, de implicações múltiplas, expande subitamente o universo da política a camadas populacionais secularmente alijadas dos negócios públicos. Porém, como sustenta Barbier, este novo público, cada vez mais amplo, torna-se também cada vez mais "anônimo" e "mediatizado" (mediatizado posto que sua reunião, meramente abstrata, se dá por via de um medium que é o impresso, e não pela agregação física dos homens em um dado lugar). Concomitantemente, surge um novo tipo de agente político, o qual se define não mais por sua relação com o príncipe e os círculos do poder, nem tampouco pelos vínculos que estabelece com seus ouvintes (sejam estes alunos de uma universidade ou fiéis de uma igreja), mas pelas mensagens escritas - e, na maior parte das vezes, impressas - que endereça ao "público moderno", junto ao qual pretende “promover pela retórica uma ação de proselitismo" - leia-se de proselitismo político ${ }^{25}$. 
Como muito bem demonstrou Barbier, a aparição deste novo personagem somente se torna inteligível à luz da transformação do "público" enquanto destinatário dos discursos políticos e símbolo da opinião comum. Entretanto, acrescentamos que sua plena inteligibilidade só se revela quando o associamos, ao mesmo tempo, à modificação do "público" enquanto comunidade política, ou seja, ao processo de consolidação e reconfiguração da coisa pública, que constitui o objeto último dos debates impressos travados na nova esfera pública de discussão.

Ao contrário do que usualmente se imagina, a sociedade lusa não se manteve à margem dessas mudanças. Em verdade, para cada uma das temáticas acima examinadas, a Restauração de Portugal constituiu um marco decisivo, quando não um ponto de nítida ruptura. Com efeito, depois da insurreição que, na manhã de $1^{\circ}$ de dezembro de 1640 , pôs fim à sexagenária união das Coroas ibéricas, os lusitanos assistiram a uma proliferação sem precedentes da atividade tipográfica no país. De súbito, multidões de panfletos, sermões, livros de história, tratados de direito, cartazes, prognósticos astrológicos, poesias, vilhancicos e outros gêneros textuais de larga circulação ${ }^{26}$ inundaram o reino, discorrendo sobre assuntos tradicionalmente ocultos sob o manto dos arcana imperii ${ }^{27}$. Nesse sentido, merece particular atenção a campanha pública de divulgação de notícias impressas que o governo tentou coordenar e que foi responsável pela publicação de mais de duas centenas e meia de relações de sucessos sobre a política e a guerra, além dos dois primeiros periódicos da história lusa: a Gazeta e o Mercurio Portuguez ${ }^{28}$.

Tal empenho publicista se insere no quadro maior daquilo que denominamos um movimento de "comunitarização" da política portuguesa - no sentido de fazer dos negócios públicos um problema de toda a comunidade -, cuja contraparte institucional foi a convocação de tal modo recorrente da assembléia das Cortes que, por mais de uma década, o reino luso se converteu em uma monarquia "quase parlamentar". O sentido de tais transformações não se pode apreender sem uma revisão crítica prévia do significado que a historiografia dominante atribuiu à ruptura política de $1^{\circ}$ de dezembro. A esse respeito, o exame de um conjunto de fontes primárias inéditas (ou largamente descuradas) oriundas dos meios plebeus permitiu-nos sustentar que, em vez de um golpe palaciano consumado por um punhado de fidalgos ávidos por mercês apoiados por clientelas obedientes e desprovidas de "autonomia social"29, a Restauração de Portugal 
foi fruto de uma aliança entre um grupo minoritário de nobres radicais e os artesãos da Casa dos 24 e da Misericórdia de Lisboa, incumbidos de mobilizar e armar a população para assegurar a tomada do palácio e das fortalezas da cidade. Donde se segue que o governo constituído em 1640 carecesse do apoio de largas fatias da aristocracia e do alto clero, fossem elas leais a Filipe IV ou não. Combatida duramente por adversários de perfis variados, a "comunitarização" da política portuguesa afigura-se, pois, uma resposta à necessidade de consolidação do poder em um contexto marcado por uma crescente politização das camadas populares e por cisões e hostilidades profundas no seio dos setores sociais em cujas mãos recaía, tradicionalmente, o timão da monarquia ${ }^{30}$.

No presente artigo, pretendemos analisar como as tensões centrais a que fizemos referência nas páginas anteriores se realizam na conjuntura específica da aclamação de D. João IV em Barcelos.

\section{Um "Santo Entrudo": a aclamação de D. João IV em Barcelos e o uso do impresso como instrumento público perante o tribunal da opinião comum}

No dia cinco de junho de 1642, Francisco de Gouveia Mendanha, membro de uma das principais famílias nobres da vila de Barcelos, apresentou ao tabelião Paulo de Carvalho um pedido singular: registrar por um instrumento público ${ }^{31}$ (o que, como vimos, corresponde a um dos sentidos clássicos de "publicar") ter sido ele "a primeira Pessoa que Levantou, e aclamou por Rey, nesta Villa de Barcellos a El Rey Dom João o Quarto Nosso Senhor"32. Para tanto, Mendanha trazia consigo um conjunto de abonadas testemunhas (padres e cônegos da Igreja Colegiada de Barcelos autorizados a depor pelo vigário-geral da corte e arcebispado de Braga) com que esperava corroborar seu relato para, enfim, esmaltar sua fama com a fé pública do Estado ${ }^{33}$.

A iniciativa de Mendanha insere-se em um contexto específico, a saber: a controvérsia acerca da identificação pública da parte que coube a cada um na "restauração" do reino de Portugal. Tal querela - em si mesma um desdobramento da luta pela hegemonia política no seio do novo regime - assumiu a forma de uma acirrada disputa pela fama de "aclamador": conscientes da íntima relação entre reputação e hierarquia social, muitos se empenharam em publicar suas alegadas façanhas em 
benefício da pátria, buscando na consagração pública de seus feitos um caminho de ascensão política, o que é por si só bastante revelador da importância que adquirira o juízo comunitário no Portugal moderno. Mas, na vila de Barcelos, além de um assunto político, a aclamação de D. João IV se tornara um caso de justiça.

Os fatos alegados por Mendanha e suas testemunhas são, em síntese, os seguintes: no dia 7 de dezembro de 1640, Francisco de Gouveia Mendanha entrou na Igreja Colegiada de Barcelos à hora das Vésperas acompanhado por várias pessoas e, batendo "com huma molleta no cham”, disse "em altas vozes - Viva El Rey Dom João Rey de Portugal". O reverendo doutor Gaspar Pinto Correa, cônego da igreja, acercou-se por sua vez de Mendanha e perguntou-lhe: "Que he isto? Vossa Mercê vem doudo? Ao que elle respondeo: falo em todo o meu Cizo - Temos ao Duque de Bragança Rey de Portugal”. Logo, “com muitas pessoas Nobres, e do Povo, Ecleziasticos, e Seculares forão por esta dita Villa e Ruas publicas della fazendo o mesmo".

Tomando ciência do que acontecia, o juiz Luiz da Cunha, que então servia em Barcelos, ameaçou Mendanha e seus correligionários "dizendo os havia de prender, e que não sabião o que fazião". Diante da hostilidade do magistrado, Mendanha dirigiu-se com um grupo de aliados à Torre dos Sinos e os fez repicar durante um espaço de meia ou uma hora. Enquanto isso, "lançarão fama os mal afectos [leia-se, os que se opunham à aclamação do duque de Bragança] que havião de tirar a cabeça a elle Francisco de Gouvea e semear-lhe suas casas de sal". Entre os opositores, destacavam-se as figuras de André de Mariz, abade de Arcozelo, e seu irmão António Faria, que com "outros seus parentes e amigos" conceberam "grande odio" contra Mendanha "pela aclamação que fez" e, valendo-se das armas da ironia e de outras manobras provocativas, tentaram desacreditar a ação dos aclamadores. Depois que estes subiram à Torre, André de Mariz aproximou-se de "dous Frades Loyos que estavão nesta Villa" e lhes "disse não fizessem caso daquilo porque andavão vebados, que senão fazião aquelas couzas senão depois do Jantar", e seguiu ameaçando os agitadores com o prenúncio dos "Tambores de Castella". Em seguida, junto ao convento do Bom Jesus, Mariz altercou com o filho de Mendanha, o cônego João Monteiro de Benevides, e proferiu "palavras mui desconcertadas e escandalozas contra a Pessoa Real de El Rey Nosso Senhor”. Os esforços foram, contudo, inúteis: a vila de Barcelos aderiu à Restauração. 
Algum tempo depois, chegando a notícia de que as tropas da Monarquia Católica de Espanha acercavam-se de Portela do Homem, na fronteira com a Galícia ${ }^{34}$, as companhias de Barcelos saem em busca do inimigo. A hipótese da invasão do reino pelas forças de Filipe IV deixa seus partidários "muidezemquietos, e soltos". Em seguida, vem aviso de que, em algumas ruas de Braga, o rei de Castela havia sido aclamado. Mendanha sai, então, pelos lugares públicos de Barcelos acompanhado de um grupo de eclesiásticos, "todos em corpo, e com Armas", aclamando D. João IV e "juntando Gente para hirem de Socorro a Braga". Antonio de Faria e os "companheiros da sua facção" riem-se da iniciativa de Mendanha e perguntam "quando se havia de acabar com aquele Santo Entrudo". André de Mariz repete a provocação dizendo que Mendanha e os seus andavam a festejar o carnaval e assegura que dentro de dois anos Portugal retornará ao domínio de Castela. Até que, parodiando os vivas dados ao novo rei, Faria grita, num ato de máxima irreverência: "viva quem quiser”! Indignado, Mendanha dá uma cutilada no irmão do abade de Arcozelo, "de que sarou sem aleijão, nem deformidade, e tudo foi por desprezar e zumbar com o mal afecto da aclamação".

Ávido por vingança, Antonio de Faria processou o agressor pela cutilada que levou e o rei, mal informado, "passou Alçada" contra Mendanha, que "padeceo (...) muitos trabalhos, gastos e vexaçoens" e sofreu grandes "moléstias" por "ser muito velho" e por serem "muitos os que o perceguião". Mas um evento dramático mudou o curso das coisas - desmantelou-se em Lisboa uma conspiração contra D. João IV $^{35}$ de que participaram dois outros irmãos de André e Antonio: o bispo de Martiria, Francisco de Faria, e o cônego de Braga e guarda-mor da Torre do Tombo, Cristovão Cogominho, ambos clientes do arcebispo de Braga Sebastião de Matos de Noronha, um dos principais líderes do complô. Enquanto isso, em Barcelos, o reverendo Gaspar da Motta Peixoto (uma das testemunhas de Mendanha) e o capitão-mor Diogo de Mello encontram André de Mariz na posse de "muitas cartas e papeis" comprometedores de seu irmão Cristovão Cogominho e o prendem, informando o rei, em seguida, da natureza dos documentos capturados. Mendanha, enfim, vê na infâmia de seus adversários um caminho para restabelecer sua reputação. Opondo o papel de primeiro plano que teve na aclamação em Barcelos à infidelidade de seus acusadores, pretende limpar seu nome apresentando a cutilada que deu em Antonio de Faria como uma questão de honra, não da honra pessoal, 
mas da honra da pátria restaurada e impunemente difamada por aqueles que agora eram tidos na conta de "traidores" 36 .

À luz do que foi discutido na primeira parte deste artigo, cabem, desde logo, algumas considerações gerais. Primeiro: a aclamação de D. João IV em Barcelos é um exemplo claro daquilo que Jouhaud e Viala intitulam "cadeias de publicação" 37 , em que usos estratégicos de mídias, símbolos e espaços se integram num processo de produção de publicidade cujos efeitos não se consumam instantaneamente, mas se desdobram no tempo por meio de uma série de atos sucessivos e interligados cuja história se pode reconstituir e que, no caso em questão, permitem marcar as etapas da transmigração da fidelidade comunitária - ou seja, da manifestação da opinião política comum. Tudo segue uma progressão e um cálculo bem definidos. $\mathrm{O}$ ato solene da aclamação do rei, para adquirir publicidade e, por conseguinte, eficácia e legitimidade, deve realizar-se aos olhos de um corpo de testemunhas que represente a comunidade. Portanto, a publicação deve enraizar-se no espaço comum da cidade, onde se congrega a coletividade: primeiro a Igreja Colegiada durante a liturgia vespertina ${ }^{38}$, depois as "ruas públicas", em seguida a torre; por fim as praças, as fontes e os templos onde a adesão da população é disputada em face das contra-aclamações dos filipistas. Mas para que a publicidade se consume, o público de testemunhas deve antes ser conclamado, o que se faz pelo uso reiterado e ritualístico dos sons e símbolos comunais: as batidas com a muleta no chão da igreja; o brado inflamado do primeiro aclamador; o clamor de sua coorte que, qual microcosmos da comunidade, comporta em si elementos de todos os corpos sociais (povo e nobreza, seculares e eclesiásticos); o repicar dos sinos para abafar a voz adversa e ameaçadora do magistrado fiel ao regime ${ }^{39}$; a guerra verbal das facções.

Segundo: contrariamente ao tom solene e altivo que caracteriza os relatos impressos da Restauração, onde normalmente se tenta estabelecer uma linha tão nítida quanto possível entre a conduta grandiloqüente dos nobres que dirigem a ação e o comportamento passional do povo, salta aos olhos aqui a marca freqüente do jocoso, do irreverente e do coloquial, seja na boca mordaz dos filipistas que difamam sistematicamente o duque de Bragança e seus aclamadores, seja nas curiosas palavras do reverendo Pinto Correa, que questiona Mendanha acerca de sua sanidade quando o ouve aclamar rei de Portugal a D. João. A passagem torna-se ainda mais interessante se a 
conjugamos com o testemunho do padre João de Medella, clérigo de missa, que sequer menciona a identidade do novo príncipe, limitando-se a declarar que Mendanha tinha, de fato, sido a primeira pessoa de quem ouvira que "tinhamos Rey Portuguez" 40 . Bem entendido, esse eloqüente silêncio parece sugerir que o traço distintivo e relevante da insurreição de 1640 para Medella era a aclamação de um "rei natural", valor profundamente arraigado na cultura portuguesa de então ${ }^{41}$, e não a restituição da Coroa alegadamente usurpada ao titular de uma casa aristocrática que não apenas tinha colaborado ativamente com o governo dos Filipes, como merecera de seus próprios aclamadores a alcunha de "grande confessor", haja vista sua notável capacidade de ouvir calado os sucessivos apelos para que aderisse ao levante separatista que então se preparava $^{42}$. Nesse sentido, é possível que aquilo que aos olhos do cônego de Barcelos parece loucura seja antes a aclamação do duque de Bragança, figura conhecida por sua tibieza, do que a ruptura com Castela.

Terceiro: importa insistir nas implicações da comparação que fazem os clientes de Sebastião de Matos de Noronha entre a Restauração e o Santo Entrudo. Nesta antiga festa portuguesa, que precedia a quaresma e a abstinência de carne que se lhe seguia, o povo se entregava aos excessos da alimentação e saía às ruas - muitas vezes portando máscaras para fazer galhofas de todo tipo. Fareladas, borrifadas de água, “combate dos projéteis de cera" recheados de líquido aromatizado (ou, nas versões mais agressivas, ovos e, quiçá, urina, como entre os escravos do Brasil), "metralha de grãos cereais ou legumes", "fato empoado de farinha", "mergulho nos tanques públicos", "alguma laranjada de garoto, que a turba aplaude e excita", e outras brincadeiras típicas como a "queima dos compadres e comadres", a "caça aos gramosilhos" e a "serração da velha"43.

Ora, a associação é clara: a crer nos depoimentos de Mendanha e suas testemunhas, André de Mariz e Antonio de Faria identificaram a Restauração de 1640 à reversão das hierarquias do carnaval popular - uma reversão que se supunha tão fugaz como a euforia irresponsável do Entrudo, a qual seria inevitavelmente silenciada tão logo os tambores bélicos de Castela impusessem novamente a quaresma da obediência, assim como haviam feito em 1637, quando os populares assumiram o controle direto de diversas vilas e cidades no curso do ciclo de revoltas desencadeado pelas Alterações de 
Évora, ou em 1580, quando os terços do duque de Alba desbarataram o exército de artesãos, regateiras e escravos libertos de D. António ${ }^{44}$.

Bem entendido, semelhante caracterização só se torna verossímil se retirarmos da escuridão um agente social de primeira grandeza, mas que não aparece no relato acima analisado senão como uma espécie de onipresença invisível, um ponto de fuga que não se divisa, mas para o qual convergem todas as linhas de ação que compõem a figura: o povo da cidade. Com efeito, é o desejo de influenciar o juízo público que dá sentido ao drama político, aos gestos teatralizados, à ocupação dos espaços urbanos, à instrumentalização dos símbolos e dos sons. É para mobilizar ou desmobilizar a população que se proferem os discursos inflamados, que se lançam os desafios, que se dizem as injúrias, que se travam os duelos. Ora, por que razão Mendanha decide tocar os sinos da vila justamente após a oposição que lhe faz o juiz filipista, senão para suscitar o engajamento do povo e usá-lo como escudo contra qualquer tentativa organizada de reação? E é precisamente neste risco de politização da plebe que reside todo o problema: para os clientes do arcebispo da senhorial cidade de Braga, D. João IV afigura-se um rei de carnaval e a insurreição de 1640 um exemplo típico do temível processo de vulgarização da política que, como apontamos, começava a subtrair-se ao monopólio dos titulados e dos altos sacerdotes para tornar-se o domínio do povo.

Entretanto, nada disso será visível para nós se nos deixarmos influenciar pelas imagens de bestialidade e irracionalidade que a cultura aristocrática de outrora atribuía aos homens de extração vulgar ${ }^{45}$ ou se não soubermos ler criticamente as ausências e nãoditos dos discursos. Com efeito, se imaginarmos a Restauração como um ato comunitariamente insignificante, uma mera troca de bastão entre elites isoladas na torre de marfim de um palácio afastado do rés do chão dos plebeus por um abismo de hierarquias intransponíveis, todo o inédito esforço de produção de publicidade que marcou os vinte e oito anos da guerra contra os castelhanos parecerá artificial, anedótico ou, quando muito, um feito meramente "literário", é dizer, de uma literatura igualmente concebida como uma torre de marfim da abstração, onde se colecionam topoï discursivos para o deleite recreativo dos eruditos. Em suma: sem o "universo" popular, a "luz comum" da tipografia assemelhar-se-á mais a uma vela decorativa do que à aurora de um novo tempo: o tempo dos modernos. 
E, em verdade, é justamente a arte tipográfica que completa e complica as cadeias de publicação da aclamação em Barcelos: é que, no bojo da explosão de notícias impressas que caracterizou os primeiros anos da guerra contra Castela, o licenciado Manoel da Rocha Freyre publicou uma relação do que tinha feito a vila de Barcelos desde a aclamação de D. João IV. Assim começa o texto, dirigindo-se ao príncipe D. Teodósio, a quem vai dedicado:

Louvores em boca propria, muito alto, \& soberano ao Senhor, estão censurados por vilezas, porem nesta occasião não incorrem esta censura os que se dirigem a acreditar fidelidades de vassalos, \& a dar animo, \& brios para a defensam da patria: E assi ainda que eu, por ser natural da Villa de Barcelos, pareça testemunha apaixonada, defendermehei com a verdade do que relato, \& com ver que na abundancia de relatores do que as outras fizerão, atè agora não ouve quem referisse o animo, com que a dita Villa aceitou a felice aclamação de $\mathrm{S}$. Magestade, \& o valor, com que a defendeu. ${ }^{46}$

A pompa das palavras não esconde a gravidade dos conflitos políticos a que se referem: a relação de Freyre é mais um dos protestos públicos feitos pelos homens e comunidades que se sentiam mal representados pela campanha pública de divulgação de notícias coordenada pelo governo do Portugal Restaurado ${ }^{47}$. Carregado de mal velada indignação pelo espaço menor que os habitantes de Barcelos vinham merecendo na pluma dos publicistas engajados na propaganda de guerra, o texto louva a coragem, a perícia militar e a fidelidade dos habitantes da vila, que estiveram entre os primeiros a aclamar o duque de Bragança ${ }^{48}$ e não hesitaram em defender, às custas dos próprios recursos, os povos do norte de Portugal das invasões inimigas ${ }^{49}$.

Mas o que acima de tudo merece destaque é o curioso paralelismo que a relação de Freyre guarda com o instrumento público de Mendanha. Em ambos os casos, o que justifica o ato de publicação é a defesa da fama. Quer se trate do renome de um homem, de uma vila ou de um reino, é a necessidade de reparar a mancha na reputação que legitima a produção da publicidade e a disputa pela opinião comum que a acompanha. Mais ainda: tanto Mendanha quanto Freyre apresentam-se como testemunhas oculares dos acontecimentos de que se pretendem relatores fiéis, mas enquanto o primeiro busca confirmar sua narrativa com a autoridade pública do Estado, o segundo ambiciona certificar seu discurso com o assentimento público da comunidade. Em outras palavras: reproduzindo a linguagem própria dos documentos judiciais, a relação de Freyre parece 
funcionar como um novo tipo de instrumento público, que se autoriza não mais pela fé pública, mas pela confiança do público moderno. O que está em jogo não é tanto o juízo dos titulares do poder, mas o do tribunal da opinião comum, árbitro último dos conflitos de uma república que caminhava, como sublinhamos, para tornar-se a coisa do povo, ainda que esse percurso não seja linear e que, em Portugal, as tendências reformistas associadas ao processo de "comunitarização" da política suscitado pela Guerra da Restauração tenham naufragado quando a celebração da paz se fez acompanhar pela ascensão de grupos dirigentes comprometidos com a preservação de uma ordem social dinástica e senhorial.

\section{Notas}

\footnotetext{
${ }^{1}$ A expressão reaparece amiúde, em versão integral ou reduzida, nos manuais de oratória e eloqüência poética da Era Moderna. Vide, por exemplo: Phrases, elegantiae poeticae, epitheta, antitheta, ex Classicis Auctoribus diligenti studio selecta. Antuérpia, 1597.

${ }^{2}$ Para uma revisão recente do sentido tradicionalmente atribuído à expressão "publicare Aventinum" e ao conteúdo da Lex de Aventino publicando, vide: MIGNONE, Lisa Marie. The Republican Aventine and Rome's Social Order. Ann Arbor: University of Michigan Press, 2016.

${ }^{3}$ GAFFIOT, Félix. Le Grand Gaffiot. Dictionnaire latin-français. Nouvelle édition revue et augmentée sous la direction de Pierre Flobert. Paris: Hachette-Livre, 2000, pp. 1288-1289. Os dicionários das línguas vernáculas publicados nos séculos XVII e XVIII ilustram bem a influência da cultura clássica sobre o vocabulário moderno. Vide, a título exemplificativo, para o que nos diz respeito mais diretamente: BLUTEAU, Raphael. Vocabulario portuguez..., vol. 8. Lisboa: Pascoal da Sylva, 1720, p. 817.

${ }^{4}$ DUMESNIL, Gardin. Synonymes latins, et leurs différentes significations... Paris: Nyon le jeune, $1788, \mathrm{p}$. 525.

${ }^{5}$ BARBIER, Frédéric. L'Europe de Gutenberg. Le livre et l'invention de la modernité occidentale (XIIIeXVIe siècle). Paris: Belin, 2006.

${ }^{6}$ STEEL, Catherine et VAN DER BLOM, Henriette (eds.). Institutions and Ideology in Republican Rome: Speech, Audience and Decision. Cambridge: Cambridge University Press, 2018; Idem (eds.). Community and Communication: Oratory and Politics in Republican Rome. Oxford: Oxford University Press, 2013; ROSILlO-LÓPEZ, Cristina. Public Opinion and Politics in the Late Roman Republic. Cambridge: Cambridge University Press, 2017; RUSSELL, Amy. The Politics of Public Space in Republican Rome. Cambridge: Cambridge University Press, 2016; MOURITSEN, Henrik. Plebs and Politics in the Late Roman Republic. Cambridge: Cambridge University Press, 2001; ARBIZU, José Mari. Res publica oppressa: política popular en la crisis de la República (133-44 a.C.). Madri: Editorial Complutense, 2000; MILLAR, Fergus. The Crowd in Rome in the Late Republic. Ann Arbor: University of Michigan Press, 1998.

${ }^{7}$ A bibliografia sobre o impacto da arte tipográfica na organização das sociedades ocidentais é vastíssima. Para uma primeira aproximação aos debates, vide: ABEL, Richard. The Gutenberg Revolution: a History of Print Culture. New Brunswick: Transaction Publishers, 2012; BOUZA, Fernando. Hétérographies. Formes de l'écrit au siècle d'or espagnol. Madri: Casa de Velázquez, 2010; MAN, John. The Gutenberg Revolution: How Printing Changed the Course of History. Londres: Bantam Books, 2009; BARBIER,
} 
Frédéric. L'Europe de Gutenberg, op. cit.; McKITTERICK, David. Print, Manuscript and the Search for Order, 1450-1830. Cambridge: Cambridge University Press, 2003; EISENSTEIN, Elizabeth L. The Printing Revolution in Early Modern Europe. Cambridge: Cambridge University Press, 1983; McLUHAN, Marshal. The Gutenberg Galaxy: the Making of Typographic Man. Toronto: University of Toronto Press, 1962; FEBVRE, Lucien et MARTIN, Henri-Jean. L'apparition du livre. Paris: Albin Michel, 1958.

${ }^{8}$ Os trabalhos sobre a política popular têm crescido bastante nas últimas décadas, sobretudo na historiografia anglo-saxã. Vide, por exemplo: JACOB, Margaret C. et SECRETAN, Catherine (eds.). In Praise of Ordinary People. Early Modern Britain and the Dutch Republic. Nova Iorque: Palgrave Macmillan, 2013; PEACEY, Jason. Print and Public Politics in the English Revolution. Cambridge: Cambridge University Press, 2013; WILLIAMSON, Fiona (ed.). Locating Agency. Space, Power and Popular Politics. Cambridge: Cambdrige Scholars Publishing, 2010; ROLLINSON, David. A Commonwealth of the People: Popular Politics and England's Long Social Revolution. Cambridge: Cambdrige University Press, 2010; WÜRGLER, Andreas. Voices from Among the 'Silent Masses': Humble Petitions and Social Conflicts in Early Modern Central Europe. In: HEERMA VAN VOSS, Lex (ed.). Petitions in social history. Cambridge: Cambdrige University Press, 2002, pp. 11-34; WOOD, Andy. Riot, Rebellion and Popular Politics in Early Modern England (Social History in Perspective). Houndsmill: Palgrave, 2002; HARRIS, Tim (ed.). The Politics of the Excluded, c. 1500-1850. Londres-Basingstoke: Palgrave Macmillan, 2001.

${ }^{9}$ BARBIER, Frédéric. História do livro. São Paulo: Paulistana, 2008, pp. 198, 213.

${ }^{10}$ Sobre a revolta napolitana de 1647, vide: HUGON, Alain. Naples insurgée 1647-1648. De l'événement à la mémoire. Rennes: Presses universitaires de Rennes, 2011 e VILLARI, Rosario. Per il re o per la patria. Roma-Bari: Laterza, 1994.

${ }^{11}$ Sobre a temática do "mundo de ponta-cabeça", vide: HILL, Christopher. The World Turned Upside Down: Radical Ideas During the English Revolution. Londres: Maurice Temple Smith, 1972.

${ }^{12}$ As ocorrências são inúmeras. A facilidade de acesso aos impressos, encontrados inclusive em meio às teias de aranhas que recobriam os cantos das cozinhas, nas mãos de aprendizes e domésticas, inspiravam a identificação entre publicação e vulgarização, tão bem ilustrada pelas recorrentes metáforas sobre os "livros vagabundos" que erravam por toda parte (PEACEY, Jason. Print and Public Politics..., op. cit., p. 4). Depois da explosão do periodismo promovida pela Guerra dos Trinta Anos, Kaspar Von Stieler, poeta alemão particularmente atento à vida dos homens de baixa condição, representa com eloqüente ironia 0 fenômeno: "os lacaios, moços de cavalariça, zeladores das cidades se reuniam para discutir jornais (...). Uma jovem mulher de Leipzig ou de Halle sabe onde se encontram os exércitos na Alemanha, na Hungria, em outros países, melhor que os políticos, e [ela] mistura à sua fala palavras estrangeiras de forma tão hábil que se poderia jurar que ela as compreendia (...)" (BARBIER, Frédéric. História do livro, op. cit., p. 245). Em seu Sueño del Infierno, Francisco de Quevedo condena os livreiros pela prática de venderem livros baratos e traduzidos em língua vulgar, permitindo que os tolos soubessem o que antes era apanágio dos sábios e levando a um estado de coisas tão esdrúxulo que até os lacaios "latinizam" e mesmo nos estábulos se podem encontrar obras de Horácio em castelhano. Em sentido análogo, o teórico da história Jerónimo de San José se queixa - referindo-se a Luiz López, pasteleiro que publicou uma crônica da cidade de Zaragoza - do triste tempo em que qualquer um ousa escrever e imprimir, não restando mais do que esperar que os sábios se façam pasteleiros e estes ocupem as tipografias ou que os sapateiros escrevam e os cronistas façam sapatos (BOUZA, Fernando. Hétérographies, op. cit., pp. 78-79).

${ }^{13}$ Durante longa data, a discussão acerca das opiniões coletivas e debates públicos na história foi marcada pela influência imperiosa da obra clássica de Jürgen Habermas (Mudança Estrutural da Esfera Pública: investigações quanto a uma categoria da sociedade burguesa. Rio de Janeiro: Tempo Brasileiro, 2003). Porém, ao longo das últimas décadas, a tese proposta pelo autor alemão vem sendo submetida a uma crítica radical. Para um primeiro contato com a imensa bibliografia sobre o assunto, vide: KAISER, Thomas E.. The Public Sphere. In: DOYLE, William (ed.). The Oxford Handbook of the Ancien Régime. Oxford: Oxford University Press, 2012, pp. 409-428; ROSPOCHER, Massimo. Beyond the Public Sphere. Opinion, Publics, Spaces in Early Modern Europe. Bolonha-Berlim: il Mulino-Duncker \& Humblot, 2012; VAN DAMME, Stéphane. Farewell Habermas? Deux décennies d'études sur l'espace public. In: BOUCHERON, Patrick et OFFENSTADT, Nicolas (eds.). L'espace public au Moyen Âge. Débats autour de Jürgen Habermas. Paris: Presses Universitaires de France, 2011, pp. 43-62; CROSSLEY, Nick et ROBERTS, John M.. After Habermas: New Perspectives on the Public Sphere. Oxford: Blackwell Publishing, 2004. 
${ }^{14}$ Sobre o tema, vide: LANDI, Sandro. 'Fama', Humors, and Conflicts. A Re-reading of Machiavelli's 'Florentine Histories'. In: ROSPOCHER, Massimo. Beyond the Public Sphere, op. cit., pp. 137-164; RIGON, Antonio et SANFILIPPO, Isa L. (eds.). Fama e publica vox nel medievo. Roma: Instituto Storico Italiano per il Medio Evo, 2011; FENSTER, Thelma et SMAIL, Daniel L. (eds.). The Politics of Talk and Reputation in Medieval Europe. Londres: Cornell University Press, 2003; ORTALLI, Gherardo. La peinture infamante du XIIIe au XVIe siècle. Paris: Gérard Monfort, 1994; GAUVARD, Claude. La Fama, une parole fondatrice. Médiévales, $\mathrm{n}^{\circ}$ 24, printemps 1993, pp. 5-13; MIGLIORINO, Francesco. Fama e infamia: problemi della società medievale nel pensiero giuridico nei secoli XII e XIII. Catania: Giannotta, 1985; MALKIEL, María Rosa Lida de. La idea de la fama en la edad media castellana. México: Fondo de Cultura Económica, 1952.

${ }^{15}$ Sobre o conceito de "Antigo Regime", vide: CHRISTIN, Olivier. Ancien Régime. Pour une approche comparatiste du vocabulaire historiographique. Mots. Les langages du politique, $\mathrm{n}^{\circ}$ 87, 2008, pp. 13-26.

${ }^{16}$ NEDERMAN, Cary J.. Freedom, Community and Function: Communitarian Lessons of Medieval Political Theory. The American Political Science Review, vol. 86, no 4, dez. 1992, pp. 977-986.

${ }^{17}$ De fato, esta dimensão inquisitorial consagrou-se institucionalmente quando, na revolução processual da Idade Média, a fama foi alçada à condição de prova judicial. Ao longo dos séculos XII e XIII, o sistema da accusatio, que estabelecia que o processo judicial só podia ser aberto sob demanda de um acusador, começou a ser substituído (ou ao menos complementado) pelo regime da inquisitio, no qual o juiz estava autorizado a agir ex officio se tomasse conhecimento de uma fama contra um suposto criminoso. Na origem desta transformação está a crença de que o crime - sobretudo o crime notório e impune - suscitava o scandalum publicum. Nesse caso, a intervenção da justiça, que sofria nesta época forte pressão da opinião comum, visava a impedir que a comunidade punisse o culpado com as próprias mãos. A idéia central, portanto, era que esta fama que assumia o papel do denunciante não podia ser "dissimulada sem escândalo, nem tolerada sem perigo", pois, como sublinha Gandinus em seu Tractatus de maleficiis, "o autor de um crime não lesa somente os interesses de sua vítima, mas também aqueles da "coisa pública da cidade" (THÉRY, Julien. Fama: l'opinion publique comme preuve judiciaire. Aperçu sur la révolution médiévale de l'inquisitoire (XIIe-XIVe siècle). In: LEMESLE, Bruno (dir.). La preuve en justice de l'Antiquité à nos jours. Rennes: PUR, 2003, pp. 132-138; GAUVARD, Claude. "De grace especial”. Crime, État et société en France à la fin du Moyen Âge. Paris: Publications de la Sorbonne, 2010). Tradução livre.

${ }^{18}$ Relaçam do assassinio intentado por Castella, contra a Magestade delRey D. João IV. Nosso Senhor, \& impedido miraculosamente. Lisboa: Paulo Craesbeeck, 1647.

${ }^{19}$ À luz do que foi dito, entende-se melhor a grande importância que possuíam nesse período a vingança e o duelo: GAUVARD, Claude et ZORZI, Andrea (eds.). La vengeance en Europe, du XIIe au XVIIIe siècle. Paris: Éditions de la Sorbonne, 2015; NASSIET, Michel. La violence, une histoire sociale: France, XVIeXVIIIe siècles. Seyssel: Champ Vallon, 2011; PELTONEN, Markku. The Duel in Early Modern England. Civility, Politeness and Honour. Cambdrige-Nova Iorque: Cambridge University Press, 2003; BRIOIST, Pascal, DRÉVILLON, Hervé et SERNA, Pierre (eds.). Croiser le fer: violence et culture de l'épée dans la France moderne, XVIe-XVIIIe siècle. Seyssel: Champ Vallon, 2002.

${ }^{20}$ BILLORÉ, Maïté et SORIA, Myriam (eds.). La Rumeur au Moyen Âge: du mépris à la manipulation, VeXVe siècle. Rennes: Presses universitaires de Rennes, 2011; NEUBAUER, Hans-Joachim. The Rumour: A Cultural History. Londres-Nova Iorque: Free Association Books, 1999; SHIBUTANI, Tamotsu. Improvised news: a sociological study of rumor. Indianápolis: Bobbs-Merrill, 1966.

${ }^{21}$ BOUZA, Fernando. Corre manuscrito. Une historia del Siglo de Oro. Madrid: Marcial Pons, 2001.

${ }^{22}$ BLUTEAU, Raphael. Vocabulario portuguez..., op. cit., p. 817.

${ }^{23}$ LETT, Didier et OFFENSTADT, Nicolas. Haro! Noël! Oyé! Pratiques du cri au Moyen Âge. Paris: Publications de la Sorbonne, 2003. Vide ainda: GAUVARD, Claude et GOKALP, Altan. Les conduites de bruit et leur signification à la fin du Moyen Âge: le charivari. Annales. Économies, Sociétés, Civilisation. 29 e année, $\mathrm{n}^{\circ} 3$, 1974, pp. 693-704.

${ }^{24}$ KANT, Immanuel. Resposta à pergunta: que é o iluminismo? In: Idem. A paz perpétua e outros opúsculos. Lisboa: Edições 70, 1988, pp. 11-19.

${ }^{25}$ BARBIER, Frédéric. Entre la plume et la presse. L'intellectuel au XVe siècle. In: RIFFAUD, Alain. L'écrivain et l'imprimeur. Rennes: Presses Universitaires de Rennes, 2010, pp. 29-31. Tradução livre. 
${ }^{26}$ CURTO, Diogo Ramada. Littératures de large circulation au Portugal (XVIe-XVIIIe siècles), LÜSEBRINK, Hans-Jürgen (ed.). Colportage et lecture populaire: imprimés de large circulation en Europe. Paris: IMEC-Éditions de la Maison des Sciences de l'Homme, 1996, pp. 299-329.

${ }^{27}$ VILLARI, Rosario. Politica barocca. Inquietudini, mutamento e prudenza. Roma-Bari: Laterza, 2010; SNYDER, Jon R.. Dissimulation and the Culture of Secrecy in Early Modern Europe. Berkeley: University of California Press, 2009.

${ }^{28}$ Ambos os periódicos encontram-se publicados: DIAS, Eurico Gomes (ed.). Gazetas da Restauração: [1640-1648]. Uma revisão das estratégias diplomático-militares portuguesas. Lisboa: MNE-ID, 2006; Idem. Olhares sobre o Mercurio Portuguez (1663-1667): transcrição e comentários, vols. 2. Lisboa: Imprensa Nacional-Casa da Moeda, 2010.

${ }^{29}$ CUNHA, Mafalda Soares da. Os insatisfeitos das honras. Os aclamadores de 1640. In: SOUZA, Laura de Mello e, FURTADO, Júnia Ferreira et BICALHO, Maria Fernanda (orgs.). O Governo dos Povos. São Paulo: Alameda, 2009, p. 491; VALLADARES, Rafael. Sobre reyes de invierno: El diciembre portugués y los cuarenta fidalgos (o alguno menos, con otros más). Pedralbes: Revista d'historia moderna, $\mathrm{n}^{\circ} 15,1995$, pp. 103-136.

${ }^{30}$ Para o desenvolvimento completo destas temáticas, vide: SARAIVA, Daniel. L'arche de l'opinion. Politque et jugement public au Portugal aux Temps Modernes (1580-1668). 2017. Tese (Doutorado em História). Université Paris IV - Sorbonne. Paris, 2017.

${ }^{31} \mathrm{O}$ instrumento público consiste em um documento oficial pelo qual um notário reconhece a autenticidade de algo que testemunhou ou dos testemunhos que recebeu sob juramento solene. Sua razão de ser é certificar que "uma ação foi realizada publicamente". Trata-se, com freqüência, de atestar a realização de um ato que, para produzir seus efeitos (os quais implicam a modificação de uma situação jurídica e a criação de uma nova cadeia de direitos e deveres), deve acontecer em público, diante de testemunhas. $\mathrm{O}$ recurso a este tipo de documento obedece, por vezes, a propósitos eminentemente políticos, como nos casos, citados por Dutour, do instrumento público que Guillaume de Nogaret fez redigir do discurso por ele proferido em 12 de março de 1303 em resposta à bula Unam sanctam do papa Bonifácio VIII e do ato notarial reconhecendo a constituição, no ano de 1364 em Dijon, de uma "facção política" e dos compromissos públicos assumidos por seus membros (DUTOUR, Thierry. L'élaboration, la publication et la diffusion de l'information à la fin du Moyen Âge (Bourgogne ducale et France royale). In: LETT, Didier et OFFENSTADT, Nicolas (eds.). Haro! Noel! Oyé!, op. cit., pp. 148-153). Tradução livre.

${ }^{32}$ SAMPAIO, José Augusto de Mancelos Pereira. 1640 em Barcelos. Barcelos: Companhia Editora do Minho Barcelos, 1938, p. 21.

${ }^{33}$ Sobre a noção de "fé pública", vide: PIERGIOVANNI, Vito (ed.). Hinc publica fides. Il notaio e l'amministrazione della giustizia. Milão: A. Giuffrè, 2006; FREYBURGER, Gérard. Fides. Étude sémantique et religieuse depuis les origines jusqu'à l'époque augustéenne. Paris: Belles Lettres, 1986.

${ }^{34}$ Segundo a relação impressa do que obraram os moradores de Barcelos desde a Restauração, que analisaremos mais adiante, o embate em Portela do Homem ocorreu em janeiro de 1641 (FREYRE, Manoel da Rocha Freire. Regra militar offerecida ao Serenissimo Principe Dom Theodosio nosso Senhor. Com hua Relaçam do que fez a Villa de Barcelos, depois que foy aclamado Rey, \& Sñor sua Magestade, atè o primeiro de Janeiro 1642. Lisboa: Domingos Lopez Rosa, 1642. Por conveniência, seguiremos aqui a transcriçãa do documento feita por SAMPAIO, José Augusto de Mancelos Pereira. 1640 em Barcelos, op. cit., p. 37).

${ }^{35}$ CUNHA, Mafalda. Elites e mudança política. O caso da conspiração de 1641. In: FRANÇA PAIVA, Eduardo (org.). Brasil-Portugal. Sociedades, culturas e formas de governar no mundo português (séculos XVI-XVIII). São Paulo: Annablume, 2006, pp. 325-343.

${ }^{36}$ SAMPAIO, José Augusto de Mancelos Pereira. 1640 em Barcelos, op. cit., pp. 18-28.

37 JOUHAUD, Christian et VIALA, Alain. Introduction. In: Idem (eds.). De la publication. Entre Renaissance et Lumières. Paris: Fayard, 2002, pp. 5-21.

${ }^{38} \mathrm{O}$ que pode ainda significar uma instrumentalização política do sagrado, na medida em que a aclamação do rei natural no momento em que os fiéis pedem socorro a Deus e agradecem-lhes os favores do dia contribuía para conferir àquela intervenção um caráter providencial.

${ }^{39} \mathrm{O}$ que também se pode interpretar como uma tomada simbólica da vila.

${ }^{40}$ SAMPAIO, José Augusto de Mancelos Pereira. 1640 em Barcelos, op. cit., p. 24. 
${ }^{41}$ Sobre a importância e os significados políticos da noção de pátria no Portugal moderno, vide: SARAIVA, Daniel. L'arche de l'opinion, op. cit., nomeadamente o segundo capítulo.

${ }^{42}$ Relação de tudo o que passou na felice aclamação do Mui Alto, \& mui Poderoso Rey Dom Ioão o IV nosso Senhor, cuja Monarchia prospere Deos por largos Annos. Lisboa: Lourenço de Anveres, 1641, p. 4.

${ }^{43}$ No "costume de Queimar os Compadres e as Comadres", fazem-se "monos de palha... os primeiros representam homens e são feitos e queimados pelas mulheres; os segundos representam mulheres e são feitos e queimados pelos homens. Os Compadres queimam-se ordinariamente nas janellas, porque os homens não os deixam sair fóra; as Comadres levam-nas espetadas pelas ruas guardadas por gente mascarada... é costume lerem-se testamentos em que os suppliciados fazem as suas deixas (...). No Alemtejo e no Algarve usa-se por occasião do Entrudo enganar os moços convidando-os para irem á Caça dos Gramosilhos ou Grambosinos; consiste o engano em leval-os para o campo, collocal-os ao pé de um agulheiro de qualquer muro com um saco na mão á espera que saia d'ali o gramosilho, especie de coelho pequeno. Os companheiros fingem que vão bater o mato, e deixam-no ali até que o rapaz cae em si conhecendo o logro. Na Extremadura e Minho esta pulha faz-se pela Serração da Velha. (...) Na Mouta a Serração da Velha apresenta uma realidade pouco agradavel para a gente avançada em edade: 'Reune-se pela manhã toda a rapaziada, munida de grandes chocas, chocalhos e campainhas, e percorre as ruas da villa em procura da velhice. Chegados que são á habitação de alguem que conta um bom par de janeiros, ahi começam a serrar (no sentido do scier,) o descuidado anachoreta... com uma infernal orchestra composta d'aquelles harmoniosos instrumentos, até que faltando a paciencia ao serrado, recorre ás armas... Trabalham bordões, servem pinceis molhados em cal, não se poupa agua a ferver, em summa, emprega o misero condemnado ao chocalho todos os meios que imagina para destroçar a terrivel phalange... só deixam a victima depois de a haverem estafado... conseguido isto eil-os ahi vão procurar novo padecente. Dura isto o dia todo e parte da noite, etc.'. As cerimonias populares da Serração da Velha variam segundo as localidades; porém sempre na noute de quarta feira da terceira semana da quaresma: 'Celebra-se á luz de archotes, com musica e algazarras, fingindo-se serrar através do corpo uma velha mettida n'um cortiço, e chamada Maria Quaresma. O testamento da velha, enfiada de pulhas em verso de pé quebrado, tem sido por muitas vezes feito e impresso. Aos gallegos boçaes, aos provincianos lorpas, e aos rapazes da rua ainda não traquejados nas cousas de Lisboa, costuma-se pregar a peça de os fazer ir para algum sitio remoto com banco ou escada ás costas, para melhor disfructarem a comica-tragedia, que se reduz ao logro, e meia duzia de cacholetas ao som de vaias". As "laranjadas" e as "brigas de Entrudo" foram, pela desordem e os excessos que promoviam, proibidas por Filipe III em alvará de 15 de dezembro de 1608 (BRAGA, Theophilo. O povo portuguez nos seus costumes, crenças e tradições, vol. II. Lisboa: Livraria Ferreira, 1885, pp. 266-270). Sobre o assunto, vide ainda: PALLA, Maria José. Análise de Maria Parda como personificação da Quaresma. Revista da Faculdade de Ciências Sociais e Humanas, nº 19. Lisboa: Edições Colibri, 2007, pp. 153-164.

${ }^{44}$ Sobre as revoltas populares no Portugal do século XVII, vide os trabalhos clássicos de OLIVEIRA, António de. Movimentos sociais e poder em Portugal no século XVII. Coimbra: IHES, 2002; Idem. Poder e oposição política em Portugal no período filipino: 1580-1640. Lisboa: Difel, 1991. Sobre a invasão do reino pelas tropas de Filipe II, vide: VALLADARES, Rafael. A conquista de Lisboa (1578-1583). Violência militar e comunidade política em Portugal. Lisboa: Texto, 2010.

${ }^{45}$ Sobre o tema, vide: MILLIOT, Vincent. Les cris de Paris ou le peuple travesti. Les représentations des petits métiers parisiens (XVIe-XVIIIe siècles). Paris: Publications de la Sorbonne, 2014; COHEN, Déborah. La nature du peuple. Les formes de l'imaginaire social (XVIIIe-XXIe siècles). Seyssel: Champ Vallon, 2010; GAUVARD, Claude, BOGLIONI, Pierre et DELFORT, Robert (eds.). Le petit peuple dans l'Occident médiéval. Terminologies, perceptions, réalités. Paris: Publications de la Sorbonne, 2002; RONZEAUD, Pierre. Peuple et représentations sous le règne de Louis XIV. Aix-en-Provence: Publications de l'Université de Provence, 1988.

${ }^{46}$ SAMPAIO, José Augusto de Mancelos Pereira. 1640 em Barcelos, op. cit., p. 36.

${ }^{47}$ A esse respeito, vide: SARAIVA, Daniel. As janelas da realidade: a função política das relações de sucessos na Guerra da Restauração de Portugal (1640-1668). In: BOADAS, Sònia et GARCÍA LÓPEZ, Jorge (eds.). Las relaciones de sucesos en los cambios políticos y sociales de la Europa Moderna. Barcelona: Universitat Autònoma de Barcelona, 2015, pp. 323-333 e Idem. O labirinto das fidelidades: o papel do teatro na campanha pública da Guerra da Restauração. In: CAMÕES, José et SOUSA, José Pedro 
(orgs.). Teatro de autores portugueses do século XVII. Lugares (in)comuns de um Teatro Restaurado. Lisboa: Centro de Estudos de Teatro da Faculdade de Letras da Universidade de Lisboa, 2016, pp. 65-88.

48 'Não foi necessaria mais q' a primeira noticia, porque sẽ esperar muita certeza, logo os moradores de Barcelos tomarão a voz do Serenissimo Senhor, \& Rey seu D. João o IV, poucos dias depois que a tomou a Cidade de Lisboa, nem ficarão àquê das outras Villas nos applausos publicos, com que festejarão aquelles primeiros dias" (SAMPAIO, José Augusto de Mancelos Pereira. 1640 em Barcelos, op. cit., p. 36).

${ }^{49}$ Notam-se ainda os sinais dos conflitos entre os poderes locais e o governador das armas, D. Gastão Coutinho, cujas vitórias são atribuídas ao concurso da gente de Barcelos: "Parece q' corre por conta de Barcelos o bêafortunado encontro, q' o General, D. Gastão Coutinho teve na Ponta das Varzeas, \& Lamas de Moure" (Ibidem, p. 38).

\section{Referências Bibliográficas}

ABEL, Richard. The Gutenberg Revolution: a History of Print Culture. New Brunswick: Transaction Publishers, 2012.

ANDERSON, Benedict. Imagined Communities: Reflections on the Origin and Spread of Nationalism. Londres: Verso, 1983.

ARBIZU, José Mari. Res publica oppressa: política popular en la crisis de la República (133-44 a.C.). Madri: Editorial Complutense, 2000.

BARBIER, Frédéric. Entre la plume et la presse. L'intellectuel au XVe siècle. In: RIFFAUD, Alain. L'écrivain et l'imprimeur. Rennes: Presses Universitaires de Rennes, 2010, pp. 21-45.

História do livro. São Paulo: Paulistana, 2008.

L'Europe de Gutenberg. Le livre et l'invention de la modernité occidentale (XIIIeXVIe siècle). Paris: Belin, 2006.

BILLORÉ, Maïté et SORIA, Myriam (eds.). La Rumeur au Moyen Âge: du mépris à la manipulation, Ve-XVe siècle. Rennes: Presses universitaires de Rennes, 2011.

BLUTEAU, Raphael. Vocabulario portuguez..., vol. 8. Lisboa: Pascoal da Sylva, 1720.

BOUCHERON, Patrick et OFFENSTADT, Nicolas (eds.). L'espace public au Moyen Âge. Débats autour de Jürgen Habermas. Paris: Presses Universitaires de France, 2011, pp. 43-62.

BOUZA, Fernando. Hétérographies. Formes de l'écrit au siècle d'or espagnol. Madri: Casa de Velázquez, 2010.

Corre manuscrito. Une historia del Siglo de Oro. Madrid: Marcial Pons, 2001.

BRAGA, Theophilo. O povo portuguez nos seus costumes, crenças e tradições, vol. II. Lisboa: Livraria Ferreira, 1885.

BRIOIST, Pascal, DRÉVILLON, Hervé et SERNA, Pierre (eds.). Croiser le fer: violence et culture de l'épée dans la France moderne, XVIe-XVIIIe siècle. Seyssel: Champ Vallon, 2002.

CHRISTIN, Olivier. Ancien Régime. Pour une approche comparatiste du vocabulaire historiographique. Mots. Les langages du politique, $\mathrm{n}^{\circ}$ 87, 2008, pp. 13-26.

COHEN, Déborah. La nature du peuple. Les formes de l'imaginaire social (XVIIIe-XXIe siècles). Seyssel: Champ Vallon, 2010. 
CROSSLEY, Nick et ROBERTS, John M.. After Habermas: New Perspectives on the Public Sphere. Oxford: Blackwell Publishing, 2004.

CUNHA, Mafalda Soares da. Os insatisfeitos das honras. Os aclamadores de 1640. In: SOUZA, Laura de Mello e, FURTADO, Júnia Ferreira et BICALHO, Maria Fernanda (orgs.). O Governo dos Povos. São Paulo: Alameda, 2009, pp. 485-505.

Elites e mudança política. O caso da conspiração de 1641. In: FRANÇA PAIVA, Eduardo (org.). Brasil-Portugal. Sociedades, culturas e formas de governar no mundo português (séculos XVI-XVIII). São Paulo: Annablume, 2006, pp. 325-343.

CURTO, Diogo Ramada. Littératures de large circulation au Portugal (XVIe-XVIIIe siècles), LÜSEBRINK, Hans-Jürgen (ed.). Colportage et lecture populaire: imprimés de large circulation en Europe. Paris: IMEC-Éditions de la Maison des Sciences de 1'Homme, 1996, pp. 299-329.

DIAS, Eurico Gomes (ed.). Gazetas da Restauração: [1640-1648]. Uma revisão das estratégias diplomático-militares portuguesas. Lisboa: MNE-ID, 2006.

Olhares sobre o Mercurio Portuguez (1663-1667): transcrição e comentários, vols. 2. Lisboa: Imprensa Nacional-Casa da Moeda, 2010.

DUMESNIL, Gardin. Synonymes latins, et leurs différentes significations... Paris: Nyon le jeune, 1788.

EISENSTEIN, Elizabeth L. The Printing Revolution in Early Modern Europe. Cambridge: Cambridge University Press, 1983.

FEBVRE, Lucien et MARTIN, Henri-Jean. L'apparition du livre. Paris: Albin Michel, 1958.

FENSTER, Thelma et SMAIL, Daniel L. (eds.). The Politics of Talk and Reputation in Medieval Europe. Londres: Cornell University Press, 2003.

FREYBURGER, Gérard. Fides. Étude sémantique et religieuse depuis les origines jusqu'à l'époque augustéenne. Paris: Belles Lettres, 1986.

FREYRE, Manoel da Rocha Freire. Regra militar offerecida ao Serenissimo Principe Dom Theodosio nosso Senhor. Com hua Relaçam do que fez a Villa de Barcelos, depois que foy aclamado Rey, \& Sñor sua Magestade, atè o primeiro de Janeiro 1642. Lisboa: Domingos Lopez Rosa, 1642.

GAFFIOT, Félix. Le Grand Gaffiot. Dictionnaire latin-français. Nouvelle édition revue et augmentée sous la direction de Pierre Flobert. Paris: Hachette-Livre, 2000.

GAUVARD, Claude et ZORZI, Andrea (eds.). La vengeance en Europe, du XIIe au XVIIIe siècle. Paris: Éditions de la Sorbonne, 2015.

"De grace especial”. Crime, État et société en France à la fin du Moyen Âge. Paris: Publications de la Sorbonne, 2010.

BOGLIONI, Pierre et DELFORT, Robert (eds.). Le petit peuple dans l'Occident médiéval. Terminologies, perceptions, réalités. Paris: Publications de la Sorbonne, 2002.

La Fama, une parole fondatrice. Médiévales, no 24, printemps 1993, pp. 5-13.

et GOKALP, Altan. Les conduites de bruit et leur signification à la fin du Moyen Âge: le charivari. Annales. Économies, Sociétés, Civilisation. 29e année, no 3, 1974, pp. 693- 704.

HABERMAS, Jürgen. Mudança Estrutural da Esfera Pública: investigações quanto a uma categoria da sociedade burguesa. Rio de Janeiro: Tempo Brasileiro, 2003. 
HARRIS, Tim (ed.). The Politics of the Excluded, c. 1500-1850. Londres-Basingstoke: Palgrave Macmillan, 2001.

HILL, Christopher. The World Turned Upside Down: Radical Ideas During the English Revolution. Londres: Maurice Temple Smith, 1972.

HUGON, Alain. Naples insurgée 1647-1648. De l'événement à la mémoire. Rennes: Presses universitaires de Rennes, 2011.

JACOB, Margaret C. et SECRETAN, Catherine (eds.). In Praise of Ordinary People. Early Modern Britain and the Dutch Republic. Nova Iorque: Palgrave Macmillan, 2013.

JOUHAUD, Christian et VIALA, Alain (eds.). De la publication. Entre Renaissance et Lumières. Paris: Fayard, 2002.

KAISER, Thomas E.. The Public Sphere. In: DOYLE, William (ed.). The Oxford Handbook of the Ancien Régime. Oxford: Oxford University Press, 2012, pp. 409-428.

KANT, Immanuel. Resposta à pergunta: que é o iluminismo?. In: Idem. A paz perpétua e outros opúsculos. Lisboa: Edições 70, 1988, pp. 11-19.

LETT, Didier et OFFENSTADT, Nicolas. Haro! Noël! Oyé! Pratiques du cri au Moyen Âge. Paris: Publications de la Sorbonne, 2003.

MALKIEL, María Rosa Lida de. La idea de la fama en la edad media castellana. México: Fondo de Cultura Económica, 1952.

MAN, John. The Gutenberg Revolution: How Printing Changed the Course of History. Londres: Bantam Books, 2009.

McKITTERICK, David. Print, Manuscript and the Search for Order, 1450-1830. Cambridge: Cambridge University Press, 2003.

McLUHAN, Marshal. The Gutenberg Galaxy: the Making of Typographic Man. Toronto: University of Toronto Press, 1962.

MIGLIORINO, Francesco. Fama e infamia: problemi della società medievale nel pensiero giuridico nei secoli XII e XIII. Catania: Giannotta, 1985.

MIGNONE, Lisa Marie. The Republican Aventine and Rome's Social Order. Ann Arbor: University of Michigan Press, 2016.

MILLAR, Fergus. The Crowd in Rome in the Late Republic. Ann Arbor: University of Michigan Press, 1998.

MILLIOT, Vincent. Les cris de Paris ou le peuple travesti. Les représentations des petits métiers parisiens (XVIe-XVIIIe siècles). Paris: Publications de la Sorbonne, 2014.

MOURITSEN, Henrik. Plebs and Politics in the Late Roman Republic. Cambridge: Cambridge University Press, 2001.

NASSIET, Michel. La violence, une histoire sociale: France, XVIe-XVIIIe siècles. Seyssel: Champ Vallon, 2011.

NEDERMAN, Cary J.. Freedom, Community and Function: Communitarian Lessons of Medieval Political Theory. The American Political Science Review, vol. 86, $\mathrm{n}^{\mathrm{o}}$ 4, dez. 1992, pp. 977-986.

NEUBAUER, Hans-Joachim. The Rumour: A Cultural History. Londres-Nova Iorque: Free Association Books, 1999.

OLIVEIRA, António de. Movimentos sociais e poder em Portugal no século XVII. Coimbra: IHES, 2002.

Poder e oposição política em Portugal no período filipino: 1580-1640. Lisboa: Difel, 1991. 
ORTALLI, Gherardo. La peinture infamante du XIIIe au XVIe siècle. Paris: Gérard Monfort, 1994.

PALLA, Maria José. Análise de Maria Parda como personificação da Quaresma. Revista da Faculdade de Ciências Sociais e Humanas, n 19. Lisboa: Edições Colibri, 2007, pp. 153-164.

PEACEY, Jason. Print and Public Politics in the English Revolution. Cambridge: Cambridge University Press, 2013.

PELTONEN, Markku. The Duel in Early Modern England. Civility, Politeness and Honour. Cambdrige-Nova Iorque: Cambridge University Press, 2003.

PIERGIOVANNI, Vito (ed.). Hinc publica fides. Il notaio e l'amministrazione della giustizia. Milão: A. Giuffrè, 2006.

Phrases, elegantiae poeticae, epitheta, antitheta, ex Classicis Auctoribus diligenti studio selecta. Antuérpia, 1597.

Relaçam do assassinio intentado por Castella, contra a Magestade delRey D. João IV. Nosso Senhor, \& impedido miraculosamente. Lisboa: Paulo Craesbeeck, 1647.

Relação de tudo o que passou na felice aclamação do Mui Alto, \& mui Poderoso Rey Dom Ioão o IV nosso Senhor, cuja Monarchia prospere Deos por largos Annos. Lisboa: Lourenço de Anveres, 1641.

RIGON, Antonio et SANFILIPPO, Isa L. (eds.). Fama e publica vox nel medievo. Roma: Instituto Storico Italiano per il Medio Evo, 2011.

ROLlinSON, David. A Commonwealth of the People: Popular Politics and England's Long Social Revolution. Cambridge: Cambdrige University Press, 2010.

RONZEAUD, Pierre. Peuple et représentations sous le règne de Louis XIV. Aix-enProvence: Publications de l'Université de Provence, 1988.

ROSILLO-LÓPEZ, Cristina. Public Opinion and Politics in the Late Roman Republic. Cambridge: Cambridge University Press, 2017.

ROSPOCHER, Massimo. Beyond the Public Sphere. Opinion, Publics, Spaces in Early Modern Europe. Bolonha-Berlim: il Mulino-Duncker \& Humblot, 2012.

RUSSELL, Amy. The Politics of Public Space in Republican Rome. Cambridge: Cambridge University Press, 2016.

SAMPAIO, José Augusto de Mancelos Pereira. 1640 em Barcelos. Barcelos: Companhia Editora do Minho Barcelos, 1938, pp. 18-32.

SARAIVA, Daniel. L'arche de l'opinion. Politque et jugement public au Portugal aux Temps Modernes (1580-1668). 2017. Tese (Doutorado em História). Université Paris IV - Sorbonne. Paris, 2017.

O labirinto das fidelidades: o papel do teatro na campanha pública da Guerra da Restauração. In: CAMÕES, José et SOUSA, José Pedro (orgs.). Teatro de autores portugueses do século XVII. Lugares (in)comuns de um Teatro Restaurado. Lisboa: Centro de Estudos de Teatro da Faculdade de Letras da Universidade de Lisboa, 2016, pp. 65-88.

As janelas da realidade: a função política das relações de sucessos na Guerra da Restauração de Portugal (1640-1668). In: BOADAS, Sònia et GARCÍA LÓPEZ, Jorge (eds.). Las relaciones de sucesos en los cambios políticos y sociales de la Europa Moderna. Barcelona: Universitat Autònoma de Barcelona, 2015, pp. 323-333. 
SHIBUTANI, Tamotsu. Improvised news: a sociological study of rumor. Indianápolis: Bobbs-Merrill, 1966.

SNYDER, Jon R.. Dissimulation and the Culture of Secrecy in Early Modern Europe. Berkeley: University of California Press, 2009.

STEEL, Catherine et VAN DER BLOM, Henriette (eds.). Institutions and Ideology in Republican Rome: Speech, Audience and Decision. Cambridge: Cambridge University Press, 2018.

(eds.). Community and Communication: Oratory and Politics in Republican Rome. Oxford: Oxford University Press, 2013.

THÉRY, Julien. Fama: l'opinion publique comme preuve judiciaire. Aperçu sur la révolution médiévale de l'inquisitoire (XIIe-XIVe siècle). In: LEMESLE, Bruno (dir.). La preuve en justice de l'Antiquité à nos jours. Rennes: PUR, 2003, pp. 119-147.

VALLADARES, Rafael. A conquista de Lisboa (1578-1583). Violência militar e comunidade política em Portugal. Lisboa: Texto, 2010.

Sobre reyes de invierno: El diciembre portugués y los cuarenta fidalgos (o alguno menos, con otros más). Pedralbes: Revista d'historia moderna, no 15, 1995, pp. 103-136. VILLARI, Rosario. Politica barocca. Inquietudini, mutamento e prudenza. Roma-Bari: Laterza, 2010.

Per il re o per la patria. Roma-Bari: Laterza, 1994.

WILliAMSON, Fiona (ed.). Locating Agency. Space, Power and Popular Politics. Cambridge: Cambdrige Scholars Publishing, 2010.

WOOD, Andy. Riot, Rebellion and Popular Politics in Early Modern England (Social History in Perspective). Houndsmill: Palgrave, 2002.

WÜRGLER, Andreas. Voices from Among the 'Silent Masses': Humble Petitions and Social Conflicts in Early Modern Central Europe. In: HEERMA VAN VOSS, Lex (ed.). Petitions in social history. Cambridge: Cambdrige University Press, 2002, pp. 11-34. 